\title{
Is Body Weight a Telltale of Preeclampsia?
}

\author{
${ }^{1}$ Neha Kumari, ${ }^{2}$ Kusum Dash, ${ }^{3}$ Roopam Singh
}

\begin{abstract}
Introduction: Increased body weight is a major epidemic for a developed country, and is also expanding to developing countries. It is measured as the body mass index (BMI). Control of body weight gain, where weight gain in adequate proportion is indicated, is a major challenge before, during, and after pregnancy.

Aim: To find out whether the increased value of BMI as measured at 20 to 24 weeks of gestation can be used to predict the development of preeclampsia.
\end{abstract}

Objective: To study the role of increased value of BMI in development of preeclampsia in normal pregnancies.

Materials and methods: A case-control retrospective study was conducted on pregnant women who attended the antenatal clinic of Bokaro General Hospital, Jharkhand, India. About 220 pregnant women, who attended the antenatal clinic, in 20 to 24 weeks of gestation, were included after proper written consent for study.

Results: About 220 patients were included in our study, who attended the antenatal clinic between 20th and 24th weeks of pregnancy. In our study, the maximum proportion of participants' BMI ranges between 22 to 24 and 24 to $26 \mathrm{~kg} / \mathrm{m}^{2}$. In our study, we found with increase of BMl value, the percentage of preeclampsia development increases.

Conclusion: In view of our results, counseling about body weight and its management should be known to the women before, during, and after pregnancy.

Keywords: Body mass index, Body weight, Preeclampsia.

How to cite this article: Kumari N, Dash K, Singh R. Is Body Weight a Telltale of Preeclampsia? J South Asian Feder Obst Gynae 2017;9(2):179-181.

\section{Source of support: Nil}

Conflict of interest: None

Date of received: 30 January 2017

Date of acceptance: 1 March 2017

Date of publication: April 2017

\section{INTRODUCTION}

Increased body weight is a major epidemic for a developed country, and is also expanding to developing

\footnotetext{
${ }^{1}$ Trainee, ${ }^{2,3}$ Senior Deputy Director

${ }^{1-3}$ Department of Obstetrics and Gynecology, Bokaro General Hospital, Bokaro Steel City, Jharkhand, India

Corresponding Author: Neha Kumari, Trainee, Department of Obstetrics and Gynecology, Bokaro General Hospital, Bokaro Steel City, Jharkhand, India, Phone: +919472957998, e-mail: yoursneha.pmch@gmail.com
}

countries. ${ }^{1}$ It is measured as body mass index (BMI). Increased value of BMI is an alarming sign for both the individual and nation as an economic burden. Control of body weight gain where weight gain is in adequate proportions is indicated, which is a major challenge before, during, and after pregnancy.

Numerous studies have been conducted to predict the development of preeclampsia or to distinguish it from more benign hypertensive complications. They include evaluation of circulating or urinary markers and imaging techniques. The World Health Organization, ${ }^{2}$ in its 2011 publication, defined criteria for diagnosis of preeclampsia as "onset of a new episode of hypertension during pregnancy, characterized by persistent hypertension (diastolic blood pressure $\geq 90 \mathrm{~mm} \mathrm{Hg}$ ) and substantial proteinuria (>0.3 g/24 hours)."

Whether weight reduction prior to pregnancy or restricting weight gain during pregnancy will reduce the risk of preeclampsia is not established. ${ }^{3}$ Many studies were conducted to show the relationship either between preeclampsia or newborn weight or overweight/obesity. A few studies were conducted to show the relationship of BMI in the normal range with development of preeclampsia. So, the present study was conducted to find out if a relation exists between development of preeclampsia and BMI within normal range.

\section{MATERIALS AND METHODS}

After institutional ethical approval, this retrospective study was conducted in the Department of Obstetrics and Gynecology, Bokaro General Hospital, Bokaro, India. About 250 pregnant women were approached with a proposal of the study. Among these, 220 patients fulfilling inclusion criteria were included in the study after taking written consent.

After taking demographic details, clinical and customized radiological examination was done. Blood pressure was measured in the high sitting position in the left upper extremity. Blood pressure had been monitored biweekly throughout pregnancy by the researcher. All populations under study were followed up regularly. Patients who were unable for regular antenatal clinic visit were allowed home-based blood pressure monitoring.

To make a meaningful comparison of BMI between pregnant women, body weight was compared as whatever recorded at the 24th week of pregnancy. 
Table 1: Age-wise distribution of patients in both groups

\begin{tabular}{lll}
\hline Age range & Preeclamptic & Nonpreeclamptic \\
\hline $15-20$ & 23 & 18 \\
$20-25$ & 27 & 39 \\
$25-30$ & 24 & 35 \\
$30-35$ & 15 & 19 \\
$35-40$ & 15 & 05 \\
Total & 104 & 116 \\
Mean \pm SD & $25.19 \pm 4.76$ & $25.52 \pm 5.32$ \\
Min-Max & $17-38$ & $16-38$ \\
d.f. & \multicolumn{2}{c}{1} \\
F-statistics & \multicolumn{2}{|c}{0.23} \\
p-value & \multicolumn{2}{|c}{0.24} \\
$\chi^{2}$-value & & 1.33 \\
t-difference & & -0.486 \\
\hline
\end{tabular}

SD: Standard deviation
Table 2: Body mass index-wise distribution of patients in both groups

\begin{tabular}{lll}
\hline$B M I\left(\mathrm{~kg} / \mathrm{m}^{2}\right)$ & Preeclamptic & Nonpreeclamptic \\
\hline $20-22$ & 6 & 15 \\
$22-24$ & 39 & 43 \\
$24-26$ & 41 & 41 \\
$26-28$ & 18 & 17 \\
Total & 104 & 116 \\
Mean \pm SD & $24.36 \pm 1.72$ & $24.03 \pm 1.85$ \\
Min-Max & $20.28-27.53$ & $20.28-27.83$ \\
d.f. & & 1 \\
F-statistics & & 1.86 \\
p-value & & 0.77 \\
$\chi^{2}$-value & & 0.572 \\
t difference & & 1.37 \\
\hline
\end{tabular}

SD: Standard deviation

\section{DISCUSSION}

In developed countries, obesity is a major epidemic, which has also extended to the developing countries. ${ }^{1}$ It is associated with profound metabolic and physiological changes. ${ }^{4}$ Preeclampsia, a significant public health threat in both developed and developing countries, contributes to maternal and perinatal morbidity and mortality globally. ${ }^{5}$

Our study, as shown in Graph 1, states that with increase in BMI, percentage of occurrence of preeclampsia increases. Most of the participants' BMI, in our study, was within the normal range, but with increase in BMI within this range, the ratios of development of preeclampsia were increased. This is corroborated with the findings of Belogolovkin et al, ${ }^{6}$ who reported that women with the lowest BMI have relatively lower preeclampsia prevalence and are protected against preeclampsia.

Further, Bodnar et $\mathrm{al}^{7}$ reported that this relationship is not limited to obese and overweight women because increases in BMI in the normal range are also associated with an increased risk of preeclampsia. that the population distribution for preeclampsia and non preeclampsia are homoscedastic with reference to age.

\section{Body Mass Index of Patients}

For comparing BMI-wise distribution of pregnant women with preeclampsia and non preeclampsia, we used ANOVA statistical tools. Table 2 shows that mean BMI along with standard deviation of both groups is unequal. The p-value at $95 \%$ CI shows insignificant difference, and also the $\chi^{2}$-value at degree of freedom 1 shows insignificant difference with reference to BMI, as table value of $\chi^{2}$ at $95 \% \mathrm{CI}$ is 3.84 , but the calculated value is 0.572 , which is very less. So, we state that the population distributions for preeclampsia and non preeclampsia are homoscedastic with reference to BMI.

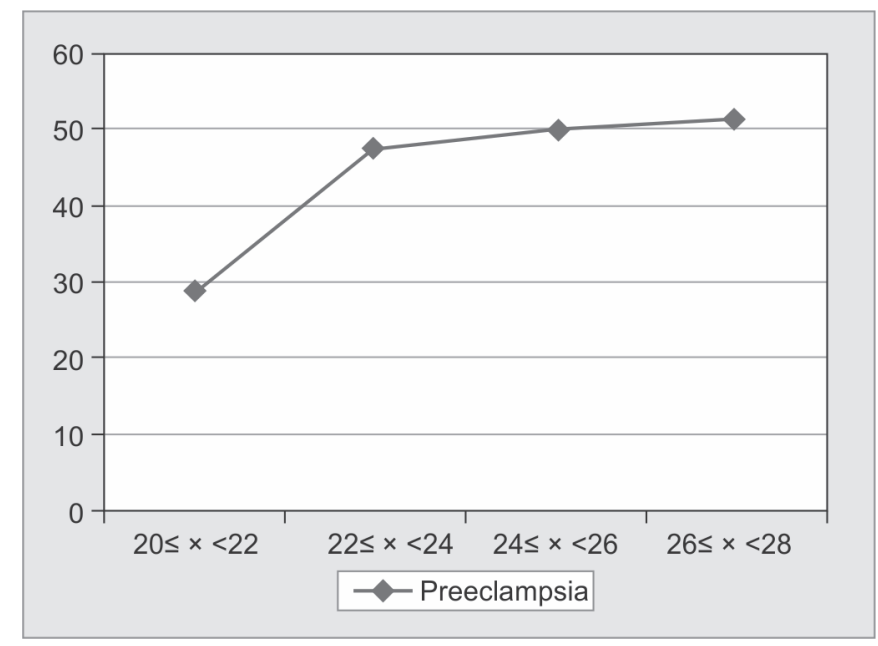

Graph 1: The role of BMI in development of preeclampsia 
Now, the open question arises as to how obesity increases the chances of preeclampsia? As reported by Roberts et $\mathrm{al}^{3}$ that the impact of weight gain in women, who subsequently develop preeclampsia, is as likely related to fluid retention as associated with preeclampsia as it is to fat accrual. It is evident from the cardiovascular literature that it is not just fat, but fat distribution, i.e., important. Central obesity, i.e., directly related to visceral obesity presents a much higher risk than peripheral obesity. ${ }^{8}$ More recent data indicate production of C-reactive protein (CRP) in adipose tissue, which is higher in obese individuals, is also elevated in early pregnancy in women, who later develop preeclampsia. ${ }^{9}$ Visceral fat produces more CRP and inflammatory cytokines ${ }^{10}$ and less leptin, contributing to oxidative stress. ${ }^{11}$ This stress leads to hypertension through reduced availability of nitrous oxide secondary to increased asymmetric dimethylarginine and oxidative stress, increased sympathetic tone, and increased expression of angiotensinogen by adipose tissue. ${ }^{12}$

The other factor that seems to be a causative factor of preeclampsia in the obese is associated with increased circulating angiogenic factors including vascular endothelial growth factor (VEGF). This likely represents spillover from production by adipose tissue, especially visceral fat. ${ }^{13}$ Because of the high circulating concentrations of soluble FMS-like tyrosine kinase 1 (sFlt1) in pregnancy, VEGF is virtually absent in the blood of pregnant women. In contrast to VEGF, placental growth factor is measurable in pregnancy and is significantly lower in midpregnancy in overweight and obese women, and this relationship is evident in women who develop preeclampsia as well as women with uncomplicated pregnancies. ${ }^{14}$

\section{CONCLUSION}

Our study concludes that increase in body weight during pregnancy increases the chance of future development of preeclampsia.

\section{RECOMMENDATION}

In what proportion weight gain is recommended should be known to every pregnant women before and during pregnancy. Every obstetric and gynecologist should monitor the ratio of weight gain and, if altered, should take attention and also inform the patient to take a major step to control.

\section{REFERENCES}

1. Misra A, Khurana L. Obesity and the metabolic syndrome in developing countries. J Clin Endocrinol Metab 2008 Nov;93 (11 Suppl 1):19-30.

2. WHO. WHO recommendations for prevention and treatment of pre-eclampsia and eclampsia. Geneva: WHO Press; 2011. p. 1-38. Available from: http://whqlibdoc.who.int/publications/2011/9789241548335_eng.pdf.

3. Roberts JM, Bodnar LM, Patrick TE, Powers RW. The role of obesity in preeclampsia. Pregnancy Hypertens 2011 Jan;1(1): 6-16.

4. Briana DD, Malamitsi-Puchner A. Adipocytokines in normal and complicated pregnancies. Reprod Sci 2009 Oct;16(10): 921-937.

5. Duley L. Maternal mortality associated with hypertensive disorders of pregnancy in Africa, Asia, Latin America and the Caribbean. Br J Obstet Gynaecol 1992 Jul;99(7):547-553.

6. Belogolovkin V, Eddleman KA, Malone FD, Sullivan L, Ball RH, Nyberg DA, Comstock CH, Hankins GD, Carter S, Dugoff $\mathrm{L}$, et al. The effect of low body mass index on the development of gestational hypertension and preeclampsia. J Matern Fetal Neonatal Med 2007 Jul;20(7):509-513.

7. Bodnar LM, Ness RB, Markovic N, Roberts JM. The risk of preeclampsia rises with increasing pre-pregnancy body mass index. Ann Epidemiol 2005 Aug;15(7):475-482.

8. Gustat J, Elkasabany A, Srinivasan S, Berenson GS. Relation of abdominal height to cardiovascular risk factors in young adults: the Bogalusa Heart Study. Am J Epidemiol 2000 May;151(9):885-891.

9. Wolf M, Kettyle E, Sandler L, Ecker JL, Roberts J, Thadhani R. Obesity and preeclampsia: the potential role of inflammation. Obstet Gynecol 2001 Nov;98(5 Pt 1):757-762.

10. Fain JN, Madan AK, Hiler ML, Cheema P, Bahouth SW. Comparison of the release of adipokines by adipose tissue, adipose tissue matrix, and adipocytes from visceral and subcutaneous abdominal adipose tissues of obese humans. Endocrinology 2004 May;145(5):2273-2282.

11. Minocci A, Savia G, Lucantoni R, Berselli ME, Tagliaferri M, Calo G, Petroni ML, de Medici C, Viberti GC, Liuzzi A. Leptin plasma concentrations are dependent on body fat distribution in obese patients. Int J Obes 2000 Sep;24(9):1139-1144.

12. Dandona P, Aljada A, Chaudhuri A, Mohanty P, Garg R. Metabolic syndrome: a comprehensive perspective based on interactions between obesity, diabetes, and inflammation. Circulation 2005 Mar;111(11):1448-1454.

13. Miyazawa-Hoshimoto S, Takahashi K, Bujo H, Hashimoto N, Saito Y. Elevated serum vascular endothelial growth factor is associated with visceral fat accumulation in human obese subjects. Diabetologia 2003 Nov;46(11):1483-1488.

14. Powers RW, Roberts JM, Plymire DA, Pucci D, Datwyler SA, Laird DM, Sogin DC, Jeyabalan A, Hubel CA, Gandley RE, et al. High pre-pregnancy body mass index is associated with low PlGF in preeclampsia and uncomplicated pregnancies. Am J Obstet Gynecol 2010 Oct;1(1):S31. 